\title{
Comparison of intravenous Paracetamol with oral Ibuprofen for medical closure of PDA (patent ductus arteriosus) in preterm newborns - can it be an effective, safe and preferable choice?
}

\author{
Kumar Rathia S. ${ }^{1}$, Kumar Kurrey V. ${ }^{2 *}$, Shrivastava S. ${ }^{3}$, Kumar Gupta A. ${ }^{4}$, Phuljhele S. ${ }^{5}$
} DOI: https://doi.org/10.17511/ijpr.2021.i01.05

\begin{abstract}
1 Santosh Kumar Rathia, Assistant Professor, Department of Trauma \& Emergency - Pediatrics, All India Institute of Medical Sciences, Raipur, Chhattisgarh, India. ${ }^{2 *}$ Virendra Kumar Kurrey, Associate Professor, ${ }^{3}$ Smit Shrivastava, Associate Professor, department of Cardiology, ${ }^{4}$ Ankit Kumar Gupta, Senior Resident, 5 Sharja Phuljhele, Professor; all authors are affiliated with the Department of Pediatrics, Pt. J. N. M. Medical College, Raipur, Chhattisgarh, India.
\end{abstract}

Introduction: In prematurely born newborns, the ductus arteriosus frequently fails to close and more than half of preterms might have Patent Ductus Arteriosus (PDA) after birth during the first 24hours. About $70 \%$ of infants born before 28 weeks may require medical or surgical closure of PDA. Objectives: To compare the effect of $\mathrm{i} / \mathrm{V}$ PCM and oral Ibuprofen on PDA closure rate in preterm neonates with a gestational age of $<37$ weeks and evaluate the side effect profile of both drugs. Material and Methods: This time-bound prospective observational study for comparison of the efficacy of the two drugs on the closure of PDA in preterms admitted during 1.5 years of the study period in a neonatal ICU caring for inborn as well as outborn neonates in central India. After approval of the institutional ethics committee, initial clinical screening included all preterms but only those with PDA (open ductus arteriosus) confirmed by 2D-echocardiography were allocated to receive either of two treatment regimens (3-day courses of each oral Ibuprofen and i/v PCM) which already exist as evidence-based therapeutic practice options. Result: Out of a total of 43 cases clinically suspected on initial screening, 30 preterm babies confirmed by 2D-Echo to have PDA were finally enrolled and analysed. Twenty-one patients received $\mathrm{i} / \mathrm{V}$ PCM with a resultant PDA closure rate of $85.7 \%$ ( $n=18 / 21)$, while nine cases could be allocated oral Ibuprofen arm and ductus closure was obtained in seven patients (77.78\%). Conclusion: Paracetamol, preferably by the intravenous route, seems to be an effective, cheap, easily available and safe first-line alternative to oral Ibuprofen for the closure of PDA, especially in newborns with extreme prematurity, who are initially intolerant to oral feeds or drugs.

Keywords: Preterm, PDA, Medical closure, Ibuprofen, Paracetamol, Intravenous

\section{Corresponding Author}

Virendra Kumar Kurrey, Associate Professor, Department of Pediatrics, Pt. J. N. M. Medical College, Raipur, Chhattisgarh, India. Email: virendra_kurrey@yahoo.com

\section{How to Cite this Article}

Rathia SK, Kurrey VK, Shrivastava S, Gupta AK, Phuljhele S. Comparison of intravenous Paracetamol with oral Ibuprofen for medical closure of PDA (patent ductus arteriosus) in preterm newborns can it be an effective, safe and preferable choice?. Pediatric Rev Int J Pediatr Res. 2021;8(1):29-38. Available From https://pediatrics.medresearch.in/ index.php/ijpr/article/view/639
To Browse

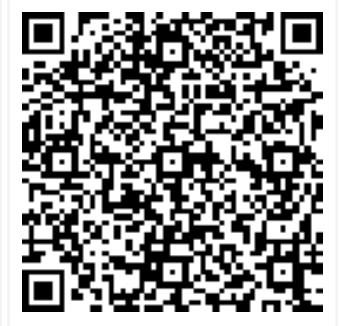

Manuscript Received 2020-12-01

Conflict of Interest No

Review Round 1
2020-12-15
Funding
Nil

Review Round 2 2020-12-25

Ethical Approval Yes
Review Round 3

Accepted 2021-01-23

Plagiarism $\mathbf{X}$-checker $9 \%$

() 2021 by Santosh Kumar Rathia, Virendra Kumar Kurrey, Smit Shrivastava, Ankit Kumar Gupta, Sharja Phuljhele and Published by Siddharth Health Research and Social Welfare Society. This is an Open Access article licensed under a Creative Commons Attribution 4.0 International License https://creativecommons.org/licenses/by/4.0/ unported [CC BY 4.0]. 


\section{Introduction}

Patent ductus arteriosus (PDA) is one of the commonest congenital heart defects caused by persistent communication between the descending aorta and the pulmonary artery that results from failure of normal physiologic closure of the fetal ductus [1]. In preterm newborns the ductus frequently fails to close and as a result, $70 \%$ of babies born before 28 weeks postmenstrual age (PMA) have PDA that require medical or surgical closure $[1,2]$.

The immature ductus arteriosus has higher sensitivity to the vasodilating effects of prostaglandins and nitric oxide [3]. PDA can be treated surgically or medically with one of prostaglandin (PG) inhibitors like Indomethacin or Ibuprofen[4]. Inhibition of PG synthesis by nonselective blockers of both cyclooxygenase (COX) 1 and 2 is effective for the non-surgical closure [5].

Indomethacin was discredited due to association with transient or permanent derangement of renal function, NEC, gastrointestinal haemorrhage or perforation, alteration of platelet function and impairment of cerebral blood flow [6,7]. Ibuprofen, a non-selective COX inhibitor, is as effective as Indomethacin in closing a PDA with reduced risk of NEC and transient renal insufficiency [8].

Another NSAID (a non-steroidal anti-inflammatory drug), Mefenamic acid, has also been reported to close a PDA[9], but no reliable randomised controlled trials have been reported. Various complications associated with Indomethacin and possibly Ibuprofen have encouraged the search for alternative drugs to treat a PDA non-surgically.

Since the late nineties only, the role of Paracetamol against prostacyclin-synthesis was known $[10,11]$, but it was suggested as an acceptable alternative drug for PDA closure in the current decade only after certain observations verified its dose dependent effectiveness $[2,12]$. Paracetamol seems to act at the peroxidase segment of PG-H2 synthetase while Ibuprofen acts on the cyclooxygenase enzyme.

Peroxidase is activated at 10 fold lower peroxide concentration than is cyclooxygenase, therefore paracetamol mediated inhibition is mediated at reduced local peroxide level concentrations (as the condition with hypoxia). Many studies mainly including small randomized trials or case series used
Paracetamol usually in cases that failed to respond to, or had contraindications for, Ibuprofen, and most of them used an oral paracetamol regimen of 15 $\mathrm{mg} / \mathrm{kg}$ per dose every 6 hours [13-18].

Non-availability of IV Ibuprofen in India is a major concern along with similar high cost and side effects of intravenous Indomethacin, whereas easy availability, less side effects, and less cost of both intravenous and oral paracetamol make this acceptable alternative. Therefore, the present study was conducted to compare the role of IV paracetamol with oral Ibuprofen for PDA closure in preterm infants.

\section{Material and methods}

After approval from Institutional Ethics Committee this prospective, observational, hospital-based study was conducted in NICU at Dr. B.R.A.M. Hospital and Pt. JNM Medical College, Raipur, CG, India between April, 2018 to September, 2019. All clinically suspected PDA cases among preterm newborns admitted during the study period were screened for eligibility, but only those confirmed by echocardiography by a cardiologist during their NICU stay (either on day 1,4 or 7 of study interventions) were finally considered into studyanalysis.

Inclusion criteria: All preterm newborns with gestation < 37 weeks with clinically suspected PDA (Confirmed to be hs-PDA by echocardiography before or during drug intervention), postnatal age limit 0 - 30 days, with parental informed consent.

All suspected cases were screened for hemodynamically significant ductus (hs-PDA) as defined by at least any one of the following to consider for study-drug interventions targeted for medical closure:

- Bounding pulses (dorsalis pedis) /widening pulse pressure

- Signs of congestive heart failure (such as gallop/cardiomegaly / pulmonary congestion)

- Hypotension requiring vasopressors, or increased ventilator support (attributed by the clinician to be primarily due to PDA)

- Echocardiographically proved hs-PDA*

*PDA was considered hemodynamically significant if the size was $\geq 1.5 \mathrm{~mm}$ at the narrowest diameter, left to right shunt across the duct, and the LA: AO ratio $>1.5: 1$. 
Final inclusion in data-analysis was considered for Echo-proven hsPDA cases only, even though the initiation of the drug was based on the above clinical criteria most of the time.

Exclusion criteria: PDA suspects in term >37weeks, structural PDA-dependent congenital heart disease, prior treatment with prophylactic Indomethacin, significant hyperbilirubinemia requiring exchange transfusion

Therapeutic drug regimens (primary interventions used for PDA closure):

Group A - Preterm newborns kept nil per oral (not on oral / tube feeding)

- IV Paracetamol: $15 \mathrm{mg} / \mathrm{kg} /$ day 6 hourly for 3days

Group B - Preterm newborns orally allowed (on oral / tube feeding)

- Oral Ibuprofen: $10 \mathrm{mg} / \mathrm{kg} /$ day on day 1,5 $\mathrm{mg} / \mathrm{kg} /$ day for day 2 and day 3

Secondary interventions: After the failure of the first course of initial intervention drug (IV PCM or oral Ibuprofen), for the second course, the drug was crossed over if no enteral route contraindication:

01. Intravenous Paracetamol after oral Ibuprofen

02. Oral Ibuprofen after Intravenous Paracetamol (if patient stabilized and orally allowed)

Intravenous Paracetamol (as the second course) after Intravenous Paracetamol (if the first course failed and the baby was yet sick, kept NPO)

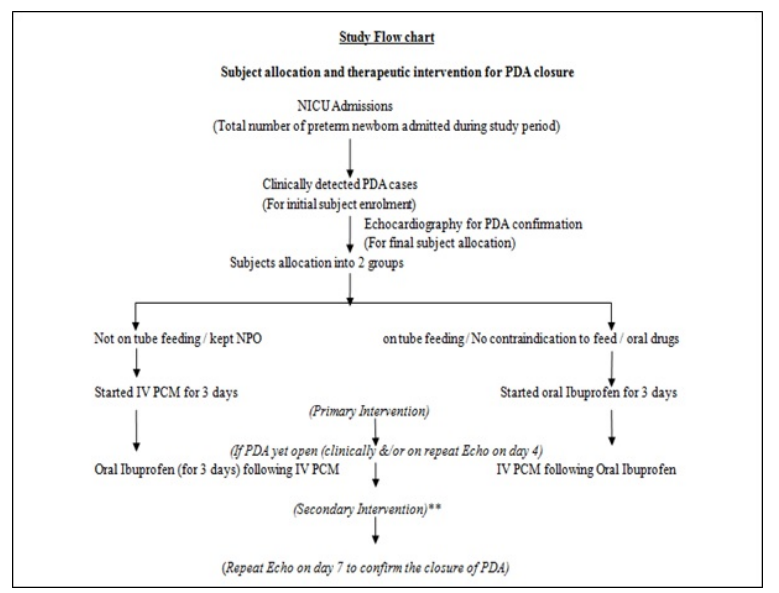

$* *$ If the patient was kept NPO, repeat the course of 3days i/v Paracetamol as the secondary intervention was started PCM group.
Primary outcome: PDA closure rate in two study arms i.e., i/v Paracetamol or oral Ibuprofen after a single 3-day course of initial intervention drugs.

Secondary outcome: Cumulative PDA closure rate with both study drugs (including the efficacy of repeat course of secondary treatment with feasible cross over of drug for non-responders), the attributable side-effect profile of each study-drug, other treatment endpoints e.g., mortality outcome, and non-closure of hs-PDA (cases requiring referral for surgical closure after 2 drug-courses of 6 days total).

\section{Method of data collection}

All preterm neonates admitted in NICU aged between 0-30 days postnatal age were enrolled after clinical suspicion on screening for signs of PDA and they underwent 2D-Echocardiography for PDA confirmation with the help of a cardiologist. But because of feasibility issues or technical delay, a few cases were started on medical treatment for PDA before 2D-Echo confirmation based on strong clinical suspicion; some of them were later excluded from the data analysis (if Echo did not detect PDA or Echo was not done at any time during treatment by day 0-7).

Eligible cases were given therapeutic intervention either Intravenous Paracetamol or Oral Ibuprofen based on their clinical condition. The primary endpoint was the PDA closure rate observed after a 3-day course of either intravenous Paracetamol or oral Ibuprofen. Secondary endpoints comprise the closure rate of PDA after the course of second/alternative treatment and the side effects of each drug intervention arms.

Echocardiography was designed to do once ideally before treatment to make a diagnosis of PDA or if possible, confirm hs-PDA (who need to be treated), then on day 4 and day 7 to rule out persistence or existence of PDA even after 3 days courses of intervention drugs. All the patient data including treatment, investigations, and outcome were recorded in predesigned proforma and compiled into Microsoft excel sheets.

\section{Data entry and analysis}

Data compilation was done in Microsoft Excel and analysed using SPSS version 20.0. The categorical data were analysed using chi-square tests, while the results of numerical data were expressed as frequency or proportions (\%), and, a p-value of $<0.05$ was taken as statistically significant. 


\section{Result}

Out of 1337 preterm newborns admitted during the study period of 1.5 years in the NICU of study setting, 43 cases had clinically suspected PDA and were initially enrolled for echocardiography confirmation of PDA, of which 30 cases (with clinically symptomatic or hs-PDA by 2D-echo) were selected for study drug-treatment allocation after excluding 13 patients due to various reasons (e.g. echo could not be done or it could not confirm PDA before and/or during first 3-day course of therapy, echo s/o CHDs with duct dependent lesion or patient died before the completion of the first course of treatment.

Table 1 below shows that amongst 30 PDA cases, female newborns were $16(53.33 \%)$ in number comparable to male preterms $(n=14,46.67 \%)$ and outborn babies were more than half $(n=17$, $56.67 \%$ ) of total PDA cases.

Table 1: Gender-distribution and place of birth of the study subjects

\begin{tabular}{|l|l|l|}
\hline \multicolumn{1}{|c|}{ Gender of study subject } & Frequency & Percentage \\
\hline Female & 16 & 53.33 \\
\hline Male & 14 & 46.67 \\
\hline Type of admission (place of birth) & \multicolumn{2}{|l|}{} \\
\hline Outborn & 17 & 56.67 \\
\hline Inborn & 13 & 43.33 \\
\hline
\end{tabular}

Table 2 shows that 16 newborns (53.33\%) amongst preterms presented with PDA had extreme prematurity with $<28$ weeks of gestational age, while $20 \%$ were of $28-32$ week, $16.67 \%$ of $32-34$ week and only $10 \%$ were $34-36$ weeks late preterms. Table 2 also shows that $56.67 \%$ of cases were ELBW (extremely low birth weight, < $1000 \mathrm{~g}$ ), $33.33 \%$ cases were Very Low BW (between birth weight $1000-1499 \mathrm{~g})$, remaining $10 \%$ cases also had low birth weight between $1500-2500 \mathrm{~g}$. Mean gestational age and birth weight of these preterm subjects was 30.54 week and $1137 \mathrm{~g}$ respectively. Thus, the incidence of PDA is much higher in lower gestational age and ELBW groups.

Table 2: Gestational age and birth weight of study subjects

\begin{tabular}{|l|l|l|}
\hline \multicolumn{1}{|c|}{ Gestational Age } & \multicolumn{1}{c|}{ Frequency } & \multicolumn{1}{c|}{ Percentage } \\
\hline$<28$ weeks & 16 & $53.33 \%$ \\
\hline $28-32$ week & 6 & $20 \%$ \\
\hline $32-34$ week & 5 & $16.67 \%$ \\
\hline $34-36$ week & 3 & $10 \%$ \\
\hline $36-37$ week & 0 & $0 \%$ \\
\hline
\end{tabular}

\begin{tabular}{|l|l|l|}
\hline Birth Weight & 17 & $56.67 \%$ \\
\hline$<1000$ grams & 10 & $33.33 \%$ \\
\hline $1000-1499$ grams & 3 & $10 \%$ \\
\hline $1500-2499$ grams & 0 & $0 \%$ \\
\hline$>2500$ grams & & \\
\hline
\end{tabular}

Table 3: Clinical features of PDA amongst study subjects

\begin{tabular}{|l|l|l|}
\hline \multicolumn{1}{|c|}{ Clinical features (s/o PDA) } & Frequency & Percentage \\
\hline Audible murmur (systolic/continuous) & 30 & 100 \\
\hline Bounding pulses (dorsalis pedis artery) & 24 & 80.00 \\
\hline Signs of CCF/fluid overload & 20 & 66.67 \\
\hline Shock/hypotension & 19 & 63.33 \\
\hline Wide pulse pressure & 18 & 60.00 \\
\hline Increased ventilatory support & 9 & 30.00 \\
\hline
\end{tabular}

Table 3 shown above indicates that the major presenting clinical features amongst preterm subjects with Echo-proven PDA were systolic/continuous murmur (100\%), bounding pulse $(80.00 \%)$, shock (63.33), wide pulse pressure in dorsalis pedis $(60 \%)$, and increased ventilator support was needed in only 9 patients (30\%). Sign of fluid overload and congestive cardiac failure (CCF) was observed in $2 / 3$ rd cases, which might be both associated risk and outcome with PDA in preterms.

Table 4: PDA closure rate after Primary intervention (first course of study drugs)

\begin{tabular}{|l|l|l|l|l|}
\hline \multicolumn{1}{|c|}{$\begin{array}{c}\text { Treatment } \\
\text { Group }\end{array}$} & \multicolumn{1}{|c|}{$\begin{array}{c}\text { Frequency } \\
(\mathbf{N})\end{array}$} & $\begin{array}{c}\text { PDA closure } \\
(\mathbf{n})\end{array}$ & \multicolumn{1}{|c|}{$\begin{array}{c}\text { Percentage } \\
(\%)\end{array}$} & $\begin{array}{c}\text { P- } \\
\text { value }\end{array}$ \\
\hline IV PCM & 21 & 18 & $85.7 \%$ & 0.593 \\
\hline Oral Ibuprofen & 9 & 7 & $77.78 \%$ & \\
\hline Total & 30 & 25 & $83.33 \%$ & \\
\hline
\end{tabular}

Table 4 depicted above summarizes the PDA closure rate in both treatment groups after the primary interventions i.e. the initial 3-day course of each drug. Amongst 21 newborns who received intravenous Paracetamol, PDA was closed in 18 $(85.7 \%)$ cases as confirmed by follow up echocardiography (on day 4), whereas oral Ibuprofen was given in 9 patients and PDA closure was obtained in 7 (77.78\%). But statistically, there was no significant difference $(p=0.593)$ between the two study drugs - intravenous paracetamol and oral ibuprofen in terms of PDA closure.

After a primary course of three-day treatment, 3 cases in the paracetamol group and 2 cases in the Ibuprofen group showed failure in PDA closure and thus they were subjected to receive another threeday course of alternative or secondary treatment option following planned cross-over allocation. 
But as table 5 reveals, out of those 5 preterm patients, only one patient was benefited with PDA closure by i/v PCM (after failed Ibuprofen therapy); while the rest four cases had certain complicating co-morbidities like sepsis, shock, pulmonary bleed, NEC (necrotizing enterocolitis, only in an Ibuprofen recipient preterm) etc. and actual PDA closure could not be documented as they succumbed before completion of second-line treatment intervention.
Even amidst all 3 patients in whom primary PCM treatment failed to close PDA were severely ill (still kept nil per oral with the risk of enteral intolerance), so considering unsuitable for crossover drug i.e. Ibuprofen (by oral route), they were started on 2nd course of I/V PCM only.

Table-5: Details of cases having PDA failed to close after primary drug course intervention

\begin{tabular}{|c|c|c|}
\hline $\begin{array}{c}\text { Treatment } \\
\text { Groups }\end{array}$ & $\begin{array}{l}\text { PDA not closed } \\
\text { after 1st drug } \\
\text { course }\end{array}$ & Secondary intervention - non-feasibility of full crossover and inconclusive result of 2 nd drug course \\
\hline $\begin{array}{l}\text { Intravenous } \\
\text { Paracetamol }\end{array}$ & 03 & $\begin{array}{l}01 \text { case died due to sepsis, } 01 \text { died of sepsis with pulmonary haemorrhage, whereas } 01 \text { left against medical advice; all } \\
\text { were started on 2nd course of i/v PCM (oral Ibuprofen contraindicated due to sickness and NPO status) - none completed } \\
\text { 3-day regimen, thus PDA closure results inconclusive. }\end{array}$ \\
\hline Oral Ibuprofen & 02 & $\begin{array}{l}\text { Both cases were given iv PCM as secondary treatment - in } 01 \text { cases PDA was closed, whereas in another case PDA was } \\
\text { not closed and died with NEC by day } 7 \text { (? after primary treatment with ibuprofen, although the patient had severe sepsis } \\
\text { with extreme prematurity as coexisting risks for that). }\end{array}$ \\
\hline
\end{tabular}

Finally, no definitive conclusion could be obtained on the actual closure rate with two study drugs after the secondary intervention, as actual cross-over of drugs was not feasible and ultimately all 05 nonresponders from both study groups received i/v PCM only. Most of these cases (4 of total 5) either succumbed to critical illness or left against advice and could not complete the second course of 3-days therapy, so we had to analyze the primary outcome of PDA closure rate in two study arms after the first course of the drugs (as shown in table 4 ).

Table 6 shows the side-effect profile in the two treatment groups. In the $\mathrm{i} / \mathrm{v}$ Paracetamol group, 01 cases each of necrotizing enterocolitis and pulmonary hemorrhage was observed, and in 07 newborns, significant hyperbilirubinemia requiring phototherapy was documented. In the oral Ibuprofen treatment group, 01 cases each of gastrointestinal bleeding, necrotizing enterocolitis (NEC), and pulmonary hemorrhage was observed along with 03 cases of hyperbilirubinemia.

\section{Table-6: Side-effects profile of iv PCM and oral Ibuprofen treatment group}

\begin{tabular}{|l|l|l|}
\hline \multicolumn{1}{|c|}{ Adverse Effects } & \multicolumn{1}{|c|}{$\begin{array}{c}\text { Intravenous } \\
\text { Paracetamol (N=21) }\end{array}$} & $\begin{array}{l}\text { Oral Ibuprofen } \\
(\mathrm{N}=9)\end{array}$ \\
\hline $\begin{array}{l}\text { Hyperbilirubinemia (requiring } \\
\text { phototherapy) }\end{array}$ & 7 & 3 \\
\hline Pulmonary Hemorrhage & 1 & 1 \\
\hline GI Bleeding & 0 & 1 \\
\hline Necrotizing enterocolitis (NEC) & 0 & 1 \\
\hline
\end{tabular}

\begin{tabular}{|l|l|l|}
\hline Total & 8 & 6 \\
\hline
\end{tabular}

Table 7 shows that in the i/v paracetamol group there was only 2 death $(2 / 21,9.52 \%)$ and amongst 9 PDA cases those got treated with oral Ibuprofen, only 1 patient $(11.11 \%)$ died. This result suggested no statistical or significant difference $(p=0.291)$ in overall mortality in the two treatment groups.

Table-7: Final survival outcomes (Mortality data) in preterm study-patients

\begin{tabular}{|l|l|l|l|}
\cline { 1 - 3 } \multicolumn{1}{|c|}{ Treatment Group } & Deaths $(\mathbf{n})$ & Percentage (\%) & P-value \\
\hline I/V paracetamol $(\mathrm{N}=21)$ & 2 & 9.52 & \multirow{2}{*}{0.291} \\
\cline { 1 - 3 } Oral Ibuprofen $(\mathrm{N}=9)$ & 1 & 11.11 & \\
\hline Total & 30 & 100 & \\
\hline
\end{tabular}

\section{Discussion}

This study aimed at comparing the efficacy of intravenous Paracetamol and oral Ibuprofen on PDA closure and evaluating the side-effect profiles of both drugs. In this study, out of 43 clinically screened PDA cases, 30 were included after confirmation of PDA by echocardiography for allocation to study-drug regimens and final analysis. In the index tertiary hospital, the total number of preterm ( $G A<37$ weeks) live births during the study period of 1.5 years was 1878 (as per the institutional delivery records) and the number of clinically detected PDA cases amongst inborn preterms was 21 (out of total 43 babies clinically screened out from total 1337 NICU admissions inborn plus outborn). 
Thus, although the incidence of clinical PDA in this hospital was around 11 per 1000 live preterm births, 2D-echo confirmed PDA cases finally analyzed as inborn cases were 13 out of 1878 (i.e. 7 per 1000 inborn preterm births) and outborn admissions contributed more than half of study subjects (17 out of total 30 patients). The actual incidence can only be calculated by a timely screening of all intramural deliveries and here in this study, it was very lower even amongst preterm newborns, when compared to other studies [19-21], which would have included all symptomatic and asymptomatic PDA detected on bedside echocardiographic screening of all preterms.

El Hajjar $M$ et al. concluded that the incidence of PDA in preterm neonates is far greater, with reports ranging from $20 \%-60 \%$ (depending on the study population and diagnostic criteria)[19], but such high data might have been extracted as PDA cases amongst the extreme preterms which required admission to NICUs.

As per Hoffman JI et al. the incidence of PDA in preterm infants was estimated to be $55 \%$ if screened at birth in the first 24 hours [20] and it might persist in as low as 57 per 100000 live births after the second week of life due to functional followed by structural closure [21]. Schneider DJ M et al. reported that the incidence of PDA in term neonates is only 1 in 2,000 births, and accounting for $5 \%-10 \%$ of all congenital heart disease [22].

Table 8 representing patient characteristics of few previous studies indicates that most of the earlier studies published were case series based observational studies or RCTs with smaller sample size and mainly including more premature and lower birth weight babies, such selection criteria may be the reason for the higher prevalence of PDA in their settings.

Table-8: The sample size and patient characteristics in various studies

\begin{tabular}{|l|l|l|l|l|}
\hline $\begin{array}{c}\text { Authors, } \\
\text { Year }\end{array}$ & $\begin{array}{c}\text { No. of PDA } \\
\text { Patients } \\
\text { enrolled }\end{array}$ & $\begin{array}{c}\text { Gestation } \\
\text { Age (in } \\
\text { weeks) }\end{array}$ & $\begin{array}{c}\text { Birth } \\
\text { Weight (in } \\
\text { grams) }\end{array}$ & $\begin{array}{c}\text { Postnatal age- } \\
\text { group (in } \\
\text { days) }\end{array}$ \\
\hline $\begin{array}{l}\text { Hammerman } \\
\text { C, 2012 [3] }\end{array}$ & 5 & $26-32$ & $720-1210$ & $3-35$ \\
\hline $\begin{array}{l}\text { Oncel MY et } \\
\text { al, 2013 } \\
{[23]}\end{array}$ & 10 & $27-34$ & $630-2970$ & $5-27$ \\
\hline $\begin{array}{l}\text { Oncel MY et } \\
\text { al, 2014 } \\
\text { [24] }\end{array}$ & 90 & $24-30$ & $590-990$ & $2-15$ \\
\hline
\end{tabular}

\begin{tabular}{|l|l|l|l|l|}
\hline Yurttutan S et al, 2013 [25] & 6 & $26-33$ & $920-1600$ & $3-7$ \\
\hline Ozdemir OM et al, 2013 [26] & 7 & $23-32$ & $620-1615$ & $20-47$ \\
\hline Sinha R et al, 2013 [1] & 10 & $27-33$ & $800-1380$ & $4-7$ \\
\hline Jasani B et al, 2013 [27] & 6 & $28-31$ & $1040-1235$ & $2-8$ \\
\hline Kessel I et al, 2014 [28] & 7 & $26-30$ & $789-1322$ & - \\
\hline Terrin G et al, 2014 [29] & 8 & $24-28$ & $551-897$ & $38-94$ (hours) \\
\hline Nadir E et al, 2014 [30] & 7 & $24-27$ & $656-951$ & $2-22$ \\
\hline Present study & 30 & $<28-36$ & $<1000-2500$ & $1-30$ \\
\hline
\end{tabular}

In this index study finally including 30 preterm patients, on comparison of the primary outcome as closure rate between two primary intervention groups, in the intravenous Paracetamol group, the PDA closure was confirmed by 2D-Echo in $18 / 21$ subjects $(85.7 \%)$; whereas in oral Ibuprofen group, PDA closure was achieved in 7 out of 9 patients $(77.78 \%)$. Although the PDA closure rate with Paracetamol was marginally high, there was no statistically significant difference in efficacy between intravenous Paracetamol and oral Ibuprofen $(p=0.593)$.

In a recent study by Al-Lawama M et al (2017), who had used oral route of paracetamol like other initial studies on the efficacy of PCM, the primary closure rate was $69 \%$ in the Paracetamol group and $78 \%$ in the Ibuprofen group and they also had not found a significant difference in the short-term neonatal outcomes [13]. Table 9 also reveals that many studies conducted in recent years have proved the acceptable efficacy or non-inferiority of Paracetamol when compared to Ibuprofen along with comparable mortality profile in two study groups.

Table-9: Studies comparing PDA closure rate and mortality outcome in Paracetamol(oral/iv) and Ibuprofen groups

\begin{tabular}{|c|c|c|c|c|c|c|}
\hline \multirow{2}{*}{ Author Year } & \multirow{2}{*}{$\begin{array}{c}\text { Sample } \\
\text { size }\end{array}$} & \multicolumn{3}{|c|}{ PDA closure rate } & \multicolumn{2}{|c|}{ Mortality } \\
\hline & & $\begin{array}{l}\text { Paracetam } \\
\text { ol group }\end{array}$ & Ibuprofe & P- & $\begin{array}{l}\text { Paracetam } \\
\text { ol group }\end{array}$ & $\begin{array}{l}\text { Ibuprofe } \\
\text { n group }\end{array}$ \\
\hline $\begin{array}{l}\text { Dang et al. } 2013 \\
{[31]}\end{array}$ & 160 & $81.2 \%$ & $78.8 \%$ & $\begin{array}{l}(P= \\
0.69)\end{array}$ & $12.5 \%$ & $15.0 \%$ \\
\hline $\begin{array}{l}\text { Oncel MY et al. } \\
2013 \text { [23] }\end{array}$ & 10 & $72.5 \%$ & $77.5 \%$ & $(P=$ & $7.5 \%$ & $5.0 \%$ \\
\hline $\begin{array}{l}\text { Oncel MY et al. } \\
2014 \text { [24] }\end{array}$ & 90 & $82.1 \%$ & $75.8 \%$ & $\begin{array}{l}(P=0 . \\
6)\end{array}$ & NA & NA \\
\hline $\begin{array}{l}\text { Al-Lawama M et } \\
\text { al. } 2017 \text { [13] }\end{array}$ & 22 & $69 \%$ & $78 \%$ & NA & $23 \%$ & $22 \%$ \\
\hline $\begin{array}{l}\text { Present study, } \\
2020\end{array}$ & 30 & $85.7 \%$ & $77.78 \%$ & $\left(\begin{array}{l}(p=0 . \\
593)\end{array}\right)$ & $9.52 \%$ & $11.11 \%$ \\
\hline
\end{tabular}

A meta-analysis ( $n=559$ infants) including five studies (Al Lawama M et al, Oncel MY et al, Dang et al, El Mashad et al, Yang et al.) reported a similar outcome with no significant difference between the 
Paracetamol and the ibuprofen groups in terms of a failure of PDA closure (the quality of evidence was moderate grade). [13,24,31,32,33]

In our index study, the all-cause mortality rate even amongst preterms with open ductus arteriosus was not very high (10\%), as only 3 patients died (out of all 30 study subjects) and 1 of clinically improving patient in primarily i/v PCM group, left against medical advice for personal reasons before completing 2nd course.

Thus, $9.52 \%$ of deaths in the $\mathrm{i} / \mathrm{v}$ PCM group and $11.11 \%$ in the oral Ibuprofen group suggested a statistically insignificant difference in mortality between the two groups $(p=0.291)$. Similarly comparable mortality outcome has been reported by a metanalysis ( $n=272$ infants) of other three old studies (Al Lawama 2017; Dang 2013; Oncel 2014) as mentioned in table $9[13,24,31]$.

Another recent study by Sunil B et al (2018) showed that paracetamol is effective on ductal closure with minimal side effects. Out of 36 preterm infants with hemodynamically significant PDA (hs-PDA) treated with intravenous paracetamol, PDA closure was achieved in 27 babies (75\%) [16]. Adriansyah R et al. had also evaluated the effect of intravenous paracetamol and found a $65.5 \%$ PDA closure rate at day 14 of evaluation [17].

Tekgunduz KS et al (2015) investigated the use of safe and effective dosing (15 mg/kg/dose) of i/v
Paracetamol for the treatment of patent ductus arteriosus in preterm infants and found that in 10 of the 13 patients $(76.9 \%)$, PDA was closed at the median 2nd day of intravenous paracetamol therapy [18].

Concerning safety concerns with the two drugs used in this study, although both have been well studied and proven safe for many pediatric indications, we had taken clearance of institutional ethics committee and took informed consent from parents of all patients. We practically observed minimal frequency of side effects in both the treatment groups, most common being hyperbilirubinemia (30 $\%$ cases in both study groups required phototherapy), one case in each group had developed serious side-effects of NEC and pulmonary bleed.

Only one additional serious side effect with the use of Ibuprofen was significant gastrointestinal bleed, but such bleeding manifestations including pulmonary hemorrhage in critical preterm patients (observed also in the recipient of $\mathrm{i} / \mathrm{v}$ paracetamol) could be attributed also to co-existing factors like sepsis, fluid overload, or failure of PDA closure, $\mathrm{CCF} /$ shock and DIC.

No other serious immediate complications like renal injury or IVH was documented in either of the study groups. Table 10 shows the comparison of the sideeffect profile of both the intervention drugs as observed in different studies.

\section{Table 10: Comparison of the safety profile of the two intervention drugs in various studies}

\begin{tabular}{|c|c|}
\hline Authors & Major side effects observed in two study groups \\
\hline $\begin{array}{l}\text { Dang et al. } \\
{[31]}\end{array}$ & $\begin{array}{l}\text { The incidence of gastrointestinal bleeding and hyperbilirubinemia was significantly higher in the Ibuprofen group compared to the paracetamol } \\
\text { group }(P<0.05) \text {. No significant differences found for other adverse events. }\end{array}$ \\
\hline Once MY & $\begin{array}{l}\text { Bilirubin and liver enzyme levels before and after each treatment course were not significantly different between groups. No patient showed } \\
\text { oliguria or AKI. }\end{array}$ \\
\hline $\begin{array}{l}\text { Al-Lawama } \\
\text { M et al. } \\
{[13]}\end{array}$ & $\begin{array}{l}\text { Favourable data showed the safety of paracetamol, although little evidence of side effects was found. None showed signs of hepatic toxicity. } \\
\text { Ibuprofen had mild vasoconstrictive side effects. }\end{array}$ \\
\hline $\begin{array}{l}\text { El Mashad } \\
\text { AER et al. } \\
{[32]}\end{array}$ & $\begin{array}{l}\text { There was a significant difference between the paracetamol and the ibuprofen groups in serum bilirubin }(\mathrm{mmol} / \mathrm{L}) \text { following treatment, with lower } \\
\text { serum bilirubin levels in the paracetamol group. }\end{array}$ \\
\hline $\begin{array}{l}\text { Present } \\
\text { study }\end{array}$ & $\begin{array}{l}\text { IV PCM group: } 7 \text { newborns (out of } 21,33 \% \text { ) developed hyperbilirubinemia (requiring phototherapy), } 1 \text { case developed necrotizing enterocolitis } \\
\text { (NEC), } 1 \text { had pulmonary bleeding (? with sepsis). Oral Ibuprofen group: } 3 \text { newborns (out of } 9 \text {, similar } 33 \% \text { ) developed hyperbilirubinemia requiring } \\
\text { phototherapy, } 1 \text { - Necrotizing enterocolitis, } \\
1 \text { - Pulmonary Hemorrhage/bleed } \\
1 \text { - GI bleeding (with coexisting sepsis). }\end{array}$ \\
\hline
\end{tabular}


Paracetamol appears to be a promisingly effective alternative to Ibuprofen for medical closure of PDA with fewer documented adverse effects over and above theoretical benefit of better safety and tolerability profile of i/v PCM.

\section{Conclusion}

For early medical closure of PDA in preterm newborns, intravenous Paracetamol is a cheap, easily available and equally effective alternate to oral Ibuprofen, with a relatively better safety profile.

The intravenous route seems to be more feasible and preferable especially amongst extremely premature and clinically sick babies, who usually can't tolerate oral feeds as well as any drugs.

\section{What this study adds to existing knowledge}

This study supports and strengthens the favourable role of intravenous paracetamol as a first-line drug for medical closure of PDA as a potentially effective, cheap and safe alternative to oral Ibuprofen, which itself is most widely used due to easy availability and less toxicity than Indomethacin.

\section{Contributions by authors}

Rathia SK conceptualized and helped in protocol writing, analyzed data, prepared and finalized the manuscript. Kurrey VK helped in conceptualization (as a guide), protocol writing, data analysis and manuscript writing, and will be the principal corresponding author.

Shrivastava $\mathrm{S}$ helped during protocol writing, concept build-up, and patient enrolment by screening \& confirmatory echocardiography. Gupta AK wrote the protocol, recruited patients and helped in data analysis and manuscript writing.

Phuljhele $\mathrm{S}$ supervised the study and helped in protocol writing and finalizing the manuscript. The final manuscript was approved by all authors.

\section{Acknowledgements}

We acknowledge the institute's neonatal intensive care unit, its medical and nursing staffs for special help on patient screening, monitoring, and routine care.

\section{Reference}

01. Sinha R, Dalal S, Negi V. An interesting observation of PDA closure with oral paracetamol in preterm neonates. J Clin Neonatol. 2013;2;30.

[Crossref]

02. Hamrick SEG, Hansmann G. Patent ductus arteriosus of the preterm infant. Pediatrics. $2010 ; 125 ; 1020-1030$.

[Crossref]

03. Hammerman C. Patent ductus arteriosusClinical relevance of prostaglandins and prostaglandin inhibitors in PDA pathophysiology and treatment. Clin Perinatol. 1995;22;457479.

[Crossref]

04. Naulty CM, Horn S, Conry J, et al. Improved lung compliance after ligation of patent ductus arteriosus in hyaline membrane disease. J Pediatr. $1978 ; 93 ; 682-684$.

[Crossref]

05. R M Mathew R. In- WW F (ed) Development of the pulmonary circulation- metabolic aspects. Philadelphia:-WB Saunders. 1998;924-9.

[Crossref]

06. Edwards AD, Wyatt JS, Richardson $C$, et al. Effects of indomethacin on cerebral haemodynamics in very preterm infants. Lancet. $1990 ; 335 ; 1491-1495$.

[Crossref]

07. Ohlsson A, Bottu J, Govan J, et al. Effect of indomethacin on cerebral blood flow velocities in very low birth weight neonates with a patent ductus arteriosus. Developmental Pharmacology and Therapeutics. 1993;20;100-106.

[Crossref]

08. OhIsson A, Walia R, Shah SS. Ibuprofen for the treatment of patent ductus arteriosus in preterm or low birth weight (or both) infants. Cochrane Database Syst Rev. 2020.

DOI: 10.1002/14651858.CD003481.pub8 [Crossref]

09. Sakhalkar VS, Merchant RH. Therapy of symptomatic patent ductus arteriosus in preterms using mefenemic acid and indomethacin. Indian Pediatr. 1992;29;313318.

[Crossref] 
10. Grèen K, Drvota V, Vesterqvist O. Pronounced reduction of in vivo prostacyclin synthesis in humans by acetaminophen (paracetamol). Prostaglandins. $1989 ; 37 ; 311-315$.

[Crossref]

11. Botting RM. Mechanism of Action of Acetaminophen- Is There a Cyclooxygenase 3 ?. Clin Infect Dis. 2000;31;S202-S210.

[Crossref]

12. El-Khuffash A, Jain A, Corcoran D, et al. Efficacy of paracetamol on patent ductus arteriosus closure may be dose dependent- Evidence from human and murine studies. Pediatr Res. $2014 ; 76 ; 238-244$.

[Crossref]

13. Al-lawama M, Alammori I, Abdelghani T, et al. Oral paracetamol versus oral ibuprofen for treatment of patent ductus arteriosus. J Int Med Res. $2018 ; 46 ; 811-818$.

[Crossref]

14. Härkin P, Härmä A, Aikio O, et al. Paracetamol Accelerates Closure of the Ductus Arteriosus after Premature Birth- A Randomized Trial. J Pediatr. 2016;177;72-77.

[Crossref]

15. Parvin Akbari Asbagh, Mohammad Reza Zarkesh, Firoozeh Nili, Fatemeh Sadat Nayeri ATN. Prophylactic teatment with oral paracetamol for patent ductus arteriosus in preterm infants- a randomized clinical trial. Tehran Univ Med J. 2018;73;4-6.

[Crossref]

16. B S, Patel S, N G. IV Paracetamol for closure of patent ductus arteriosus in preterm neonates admitted to a tertiary care centre. Int J Contemp Pediatr. 2018;5;294.

[Crossref]

17. Rizky Adriansyah, Nikmah S Idris, Mulyadi M Djer, Sukman T, Putra RR. Intravenous paracetamol and patent ductus arteriosus closure in preterm infants. Paediatr Indones. $2011 ; 51 ; 207-212$.

[Crossref]

18. Tekgündüz KŞ, Ceviz N, Caner $\mathrm{I}$, et al. Intravenous paracetamol with a lower dose is also effective for the treatment of patent ductus arteriosus in pre-term infants. Cardiol Young. 2015;25;1060-1064.

[Crossref]
19. El Hajjar M, Vaksmann G, Rakza T, et al. Severity of the ductal shunt- A comparison of different markers. Arch Dis Child Fetal Neonatal Ed. 2005 Sep;90(5)F419-22.

[Crossref]

20. Hoffman JIE, Kaplan S. The incidence of congenital heart disease. J Am Coll Cardiol. 2002;39;1890-1900.

[Crossref]

21. Clyman RI. Mechanisms regulating the ductus arteriosus. Biol Neonate. 2006;89;330-335. [Crossref]

22. Schneider DJ, Moore JW. Patent ductus arteriosus. Circulation. 2006;114;1873-1882. [Crossref]

23. Oncel MY, Yurttutan S, Degirmencioglu $H$, et al. Intravenous paracetamol treatment in the management of patent ductus arteriosus in extremely low birth weight infants. Neonatology. $2013 ; 103 ; 166-169$.

[Crossref]

24. Oncel MY, Yurttutan S, Erdeve O, et al. Oral paracetamol versus oral ibuprofen in the management of patent ductus arteriosus in preterm infants- A randomized controlled trial. J Pediatr. 2014;164;1-2.

[Crossref]

25. Yurttutan S, Oncel MY, Arayici $S$, et al. A different first-choice drug in the medical management of patent ductus arteriosus- Oral paracetamol. J Matern Neonatal Med. $2013 ; 26 ; 825-827$.

[Crossref]

26. Özdemir ÖM, Dog `an $M$, Küçüktaşçi K, et al. Paracetamol therapy for patent ductus arteriosus in premature infants- A chance before surgical ligation. Pediatr Cardiol. 2014;35;276279.

[Crossref]

27. Jasani B, Kabra N, Nanavati RN. Oral paracetamol in treatment of closure of patent ductus arteriosus in preterm neonates. J Postgrad Med. 2013;59;312-314.

[Crossref]

28. Kessel I, Waisman D, Lavie-Nevo K, et al. Paracetamol effectiveness, safety and blood level monitoring during patent ductus arteriosus closure- A case series. J Matern Neonatal Med. 2014;27;1719-1721.

[Crossref] 
29. Terrin G, Conte F, Scipione A, et al. Efficacy of paracetamol for the treatment of patent ductus arteriosus in preterm neonates. Ital J Pediatr. 2014;40;1-2.

[Crossref]

30. Nadir E, Kassem E, Foldi S, et al. Paracetamol treatment of patent ductus arteriosus in preterm infants. J Perinatol. 2014;34;748-749.

[Crossref]

31. Dang D, Wang D, Zhang C, et al. Comparison of oral paracetamol versus ibuprofen in premature infants with patent ductus arteriosus- A randomized controlled trial. PLoS One. $2013 ; 8 ; 1-2$.

[Crossref]
32. El-Mashad AER, El-Mahdy H, El Amrousy D, et al. Comparative study of the efficacy and safety of paracetamol, ibuprofen, and indomethacin in closure of patent ductus arteriosus in preterm neonates. Eur J Pediatr. 2017;176;233-240. [Crossref]

33. Yang B, Gao X, Ren Y, et al. Oral paracetamol vs oral ibuprofen in the treatment of symptomatic patent ductus arteriosus in premature infants- A randomized controlled trial. Exp Ther Med. $2016 ; 12 ; 2531-2536$.

[Crossref] 